\title{
La querella de la guerra sucia y Guerra en el Paraíso
}

\section{The Complaint of the Dirty War and Guerra en el Paraíso}

\author{
José Eduardo Serrato Córdova \\ Instituto de Investigaciones Filológicas, UNAM \\ jesc@unam.mx
}

RESUMEN: En este trabajo propongo releer la novela de Carlos Montemayor, Guerra en el Paraíso, abordando la manera en que conceptos como "guerra sucia" y "derechos humanos" han ingresado en la agenda política democrática de México. A veintisiete años de publicada la obra podemos encontrar detalles en su argumentación que la convierten en una narración

Palabras clave: retórica del derecho; literatura; política; guerra sucia; Lucio Cabañas. que guardó la memoria colectiva de las víctimas de la represión militar.

ABSTRACT: In this paper I propose to reread the novel Guerra en el Paraíso alongside with the way concepts

KEYWORDS: Rhetoric of law;

Literature;

Politics;

Dirty war; Lucio Cabañas. such as "dirty war" and "human rights" have entered the democratic political agenda of Mexico. Twentyseven years after the publication of the work, we can find details in its argumentation that turn it into a narrative that kept the collective memory of the victims of military repression.

recepción: 24 agosto 2017.

aceptación: 30 mayo 2018. 


\section{La importancia de la opinión pública en la mentalidad democrática}

Sólo los locos, los teóricos puros o los aprendices dejan de tener en cuenta la opinión pública

JACQUES NECKER (1732-1804), ministro de Hacienda de la corona francesa

Este trabajo no es estrictamente de crítica literaria; es un ensayo que comenta Guerra en el Paraíso en relación con la historia de la paulatina aceptación de los conceptos de "guerra sucia" y "guerra de baja intensidad" en la opinión pública y en la conciencia democrática nacional. Por más de veinte años, el discurso oficial del estado mexicano se negó sistemáticamente a aceptar que en la lucha contra la guerrilla del Partido de los Pobres, encabezada por el profesor Lucio Cabañas Barrientos, implementó tácticas antiguerrillas empleadas en Vietnam, y que en México se ensayó un sistema de violencia militar muy parecido al de la Operación Cóndor, que usaron las dictaduras sudamericanas. Los jefes policíacos del gobierno de Luis Echeverría ofrecieron la versión de que los efectivos de la Brigada de Ajusticiamiento fueron delincuentes comunes y, hasta fecha reciente, no se les reconocía el estatus de combatientes. Los familiares de los afectados y algunos sobrevivientes han actuado en diversos tribunales internacionales para que se les haga justicia, pero debían tener el respaldo moral de la sociedad civil para que sus reclamos tuvieran "legitimidad". Es en este contexto, el de la querella por la aceptación de que sí existió una verdadera represión militar en el estado de Guerrero, que interpreto la novela Guerra en el Paraíso, de Carlos Montemayor, como una ficción planeada para demostrar en qué consistieron los crímenes de guerra de este virtual golpe de estado que se vivió en la zona serrana guerrerense; espacio, que por cierto, sigue siendo muy conflictivo en la actualidad.

Por otro lado, a veintisiete años de publicada la novela de Montemayor, han aumentado los estudios sobre la memoria colectiva, como es el caso de Tiempo pasado, de Beatriz Sarlo, en donde se propone otro tipo de lectura de obras que habían sido encasilladas como testimoniales y no se 
había hecho una hermenéutica más amplia para entender los lazos entre el autor y la colectividad que queda representada en el texto. En el caso de Guerra en el Paraíso, los primeros reseñistas no pasaron de considerarla una obra del "realismo romántico", representante del maniqueísmo del realismo socialista. La novela en absoluto es un elogio de la personalidad histórica de Lucio Cabañas. Por el contrario, como verdadera novela histórica cumple con un riguroso trabajo de archivo y de campo, no sólo con el fin de documentar la vida del guerrillero sino para documentar también los años de la guerra sucia y denunciar a los culpables. Gracias a la obra La era del testigo, de Annette Wieviorka, valoramos de otra manera el punto de vista del testigo, es decir, la opinión del hombre común que vivió en carne propia la represión o presenció un crimen; ésta puede importar tanto en la opinión pública como el análisis de un especialista universitario. Guerra en el Paraíso está compuesta de muchas voces anónimas que como un coro griego van exponiendo los motivos del crimen. Desde la tragedia griega, el vocabulario y la argumentación del derecho eran empleados en los parlamentos de obras como Antígona, de Sófocles. Como veremos, la retórica jurídica en Guerra en el Paraíso tiene como propósito convencer a una audiencia de que en el México democrático de los años setenta, en el país que recibía exiliados y perseguidos políticos, y que presumía de su liderazgo entre los países del Tercer Mundo y de sus alianzas con las naciones No Alineadas, hubo una guerra de exterminio de baja intensidad contra poblaciones rurales. Y, por otra parte, andando el tiempo la novela también ha tenido un lugar destacado como reservorio de la memoria colectiva, dado que los hechos que Montemayor narra están documentados con testimonios e investigaciones en archivos confidenciales a los que muy pocos tenían acceso.

Los crímenes de Estado perpetrados en Guerrero fueron ocultados por más de veinte años, pero periodistas, familiares y escritores profesionales, como es el caso de Carlos Montemayor, guardaron el testimonio de los abusos del ejército. ${ }^{1}$ Aunque no fue una acción coordinada, se logró

1 Recordemos que la novela tuvo resonancia internacional ya que fue traducida a varios idiomas y en cierto modo se tomó como una premonición de la guerrilla zapatista chiapaneca que se dio a conocer tres años después de publicada Guerra en el Paraíso. 
que en 2006 se formara la Comisión de la Verdad. El proceso para que el tema de la guerra sucia, como sucedió en el caso argentino, ingrese a la agenda pública, es arduo, pero el caso mexicano ha sido penoso y lento porque el monopolio de la información y la manipulación de la opinión ha sido un coto cerrado que apenas ha empezado a fracturarse. Considero que podemos hacer una relectura de Guerra en el Paraíso como una obra que presenta al lector como el miembro de un jurado, que escucha las versiones del caso, vertidas por víctimas e inculpados para que saque sus conclusiones. De este modo, la estrategia narrativa de Carlos Montemayor tiene las marcas textuales de un juicio formal, con presentación de pruebas y refutación de hechos.

El teórico del derecho José Calvo comenta en su obra Derecho y narración que durante un juicio la exposición de los hechos sometidos a proceso debe traducirse en una narración mimética para que los miembros del jurado comprendan las causas y efectos de los acontecimientos. Esta es una de las causas por las que los personajes de Montemayor nos resultan un tanto didácticos, puesto que en las acciones de los actores hay una explicación y luego una refutación de sus ideas, en una relación dialéctica que culmina con una antítesis que revela la "verdad" de los hechos.

La opinión pública bien informada es inseparable de la mentalidad democrática y requiere de ciudadanos preocupados por conocer los sucesos de su comunidad. El prólogo del libro La guerra sucia en México y el papel del poder Legislativo. Comparativo internacional (Zazueta Aguilar 2009) deja en claro la necesidad de conocer los abusos del Estado y del ejército durante la "guerra sucia" mexicana y es la primera ocasión que un grupo parlamentario reconoce que hubo una guerra de baja intensidad en suelo mexicano: "Publicar un libro con el tema de la guerra sucia — es decir, la política de exterminio emprendida en contra de disidentes y población civil por parte del Estado-, en la época actual parecería ser extemporáneo. Sin embargo, su vigencia reside en el hecho de que no se conoce toda la verdad sobre este período oscuro de nuestra historia y que los perpetradores de crímenes contra la humanidad siguen impunes" (7). Este hecho significa, sin duda, un triunfo, parcial, limitado, pero triunfo al fin, de la opinión pública democrática contra el 
autoritarismo del estado mexicano y contra los abusos del ejército sobre la población civil.

Guerra en el Paraíso se adelantó en el tiempo a los legisladores y ahora podemos entender las propuestas que sobre derechos humanos, memoria colectiva y sucesos de la guerra sucia de los años setenta había dejado entrever Carlos Montemayor al relatar la vida de Lucio Cabañas Barrientos. Cuando en 1991 la editorial Diana publicó la primera edición de Guerra en el Paraíso, la recepción inicial no fue muy buena. Traigo a colación dos reseñas de publicaciones radicalmente distintas en lo político; una fue Vuelta y la otra Nexos. Fernando García Ramírez, en la primera, no escatimó sarcasmos para mofarse de una novela que calificó de maniquea y en la que se hacía un elogio desmedido del "guerrillero heroico" que luchaba contra las fuerzas oscuras del mal, el Estado mexicano: "el Estado aparece representado por políticos crueles, corruptos ambiciosos, y por el ejército, ciega maquinaria represiva" (39). Por su parte, Roberto Pliego rechazó la novela por su falta de calidad literaria. Con la ironía peculiar del reseñista describe los defectos de la narración de esta manera: "¿vale la pena demorarse con tanto cuidado — casi la mitad del libro- en consignar las vejaciones y los crímenes contra los campesinos? ¿Por qué Lucio habla como sociólogo rural y los funcionarios del gobierno como oradores del día de la bandera? Por el propósito de hacerlos reales, Montemayor sacrifica la complejidad de sus personajes y disminuye al mínimo sus recursos expresivos" (1991). No quiero poner en evidencia a los reseñistas citados, sólo los menciono como una muestra significativa de cómo gente letrada, de nivel universitario y en pleno 1991 no sólo no consideraba la acción militar en Guerrero como una "guerra sucia", sino que ni siquiera se mencionaba la defensa de los "derechos humanos" y menos aún se pensaba en la preservación de la memoria colectiva de los sucesos. 


\section{Breve historia de la querella de la aceptación de la guerra sucia en México ${ }^{2}$}

Si revisamos algunos de los títulos de libros sobre temas políticos notaremos que aparece el debate sobre cómo definir la represión armada contra campesinos en Guerrero y la aplicación del recurso de tierra rasa para aislar las comunidades que apoyaban la guerrilla del Ejército de los Pobres a finales de la década de los años setenta. Algunos periodistas se apropiaron del concepto de "guerra sucia" tomado directamente de la experiencia argentina, para definir la actuación del Estado mexicano contra los grupos subversivos. ${ }^{3} \mathrm{~A}$ finales de los ochenta, después de que se asentó la reforma política impulsada por el gobierno de José López Portillo, parientes de desaparecidos políticos y algunos activistas de derechos humanos - término por cierto que aún no aparecía en la legislación nacional— ${ }_{1}^{4}$ iniciaron la documentación sobre víctimas del ejército mexicano y su proceder contra

2 Muchos sociólogos y periodistas han definido la represión militar de los años setenta en Guerreo como una "guerra sucia", al estilo chileno, argentino, salvadoreño o guatemalteco. En cambio, otros estudiosos del tema hablan que más bien se debería definir como una "guerra de baja intensidad". Adrián Galindo de Pablo señala que "la Guerra de Baja Intensidad es una estrategia contrainsurgente desarrollada y perfeccionada a partir de las guerras imperiales estadunidenses desatadas en la segunda mitad del siglo xx. La guerra de Vietnam, que comenzó en 1962 y terminó oficialmente en 1973, fue la primera guerra en donde se aplicó este tipo de guerra prolongada de desgaste. Para que se pueda dar este tipo de guerra es necesaria la existencia de movimientos o gobiernos contrahegemónicos con un profundo arraigo popular que se opongan o resistan a intereses coloniales o imperialistas". Carlos Marín Beristáin y Francesc Riera citados por Galindo de Pablo, subrayan que "los mecanismos de la represión son dirigidos a contener y condicionar a los pueblos, alterando sus valores para alcanzar objetivos y proyectos a través de la dominación y el terror [...] Es decir, romper el tejido colectivo y solidario de las organizaciones populares [...] Estos mecanismos represivos desarrollan una acción psicológica que genera en la población una actitud culposa de la situación, y la necesidad de que los militares pongan 'orden' al desquicio social y la subversión" "Guerra de baja intensidad", en Animal Político, consultado en línea).

3 Jorge Mendoza García describe la guerra sucia mexicana como la táctica violenta del Estado en el que éste combinó "prácticas [tanto] legales como ilegales, que incluían la detención ilegal, la tortura, la reclusión en cárceles clandestinas e incluso la desaparición".

${ }_{4}$ El 6 de junio de 1990, por decreto presidencial, se creó la Comisión Nacional de Derechos Humanos y fue presidida por el doctor Jorge Carpizo por tres años, de 1990 a 1993. Información tomada de la página <http://www.cndh.org.mx/Antecedentes> [consultada el 15 de abril de 2018]. 
la guerrilla de Lucio Cabañas. Tanto el ejército mexicano como la Dirección Federal de Seguridad fueron los torturadores de guerrilleros y de campesinos simpatizantes durante la guerra sucia. Apenas el 18 de junio del 2002, el Archivo General de la Nación puso a disposición del público información relacionada con la guerra sucia (Alejandro Jiménez Martín del Campo en Castellanos: 318); a los pocos años, en el 2006, el Estado prohibió de nuevo el acceso a la información.

Regresando a las argumentaciones de Beatriz Sarlo, la crítica nos habla de la "posmemoria" y la "memoria vicaria", que son los recuerdos que relatan no los testigos directos, sino los herederos que conocen hechos no revelados. En el caso que nos ocupa nos es muy útil retomar la idea de "memoria vicaria", como memoria prestada para documentar lo que los testigos no pudieron decir. Carlos Montemayor se interesó en recrear los episodios de tortura del ejército mexicano contra campesinos que eran acusados de apoyar la guerrilla del Partido de los Pobres. En lo que significó un tour de force, el novelista, como depositario "vicario" de la memoria de las víctimas que fueron ejecutadas en el tristemente célebre "avión de la muerte", denunció lo que muchos años después fue demostrado con los hallazgos de los archivos secretos del ejército mexicano y de la Dirección Federal de Seguridad, que para intimidar a la población civil, los sospechosos de ser subversivos eran arrojados al mar. Los restos humanos regresaban a tierra firme y los pescadores guardaron la evidencia para que algún día se diera a conocer la manera en que actuaron las fuerzas armadas.

Hoy día contamos con dos libros que son una joya documental, La charola, de Sergio Aguayo, y México armado, de Laura Castellanos, quienes informan de las prácticas violentas tanto de las fuerzas armadas como de la policía política del estado (la siniestra DFS), dirigida por el criminal Miguel Nazar Haro, torturador profesional que laboró para el Estado por más de cuarenta años. Un hecho particularmente siniestro es que los testimonios sobre la tortura nos demuestran que las vejaciones con la picana y el uso del llamado vuelo de la muerte fueron técnicas probadas primero en México y luego exportadas. Las coincidencias de lo que los investigadores encontraron en los archivos con las descripciones que realizó Montemayor son enormes. Se hace evidente que Montemayor tuvo acceso a archivos confidenciales del ejército y los utilizó en su novela. 
Alejandro Jiménez Martín del Campo (2007) se ha encargado de documentar el proceso que la sociedad civil ha llevado contra el ejército y los ex miembros de la Dirección Federal de Seguridad. Como lo establece el trabajo de Jiménez Martín del Campo, durante más de veinte años se negó que en la lucha contra el Ejército de los Pobres y la Liga Comunista 23 de Septiembre se hayan practicado torturas y ejecuciones. Uno de los propósitos de la retórica de Guerra en el Paraíso es convertir al lector en testigo de las atrocidades cometidas por el ejército que de facto tuvo el poder absoluto del estado de Guerrero. Además, recordemos que Montemayor no sólo describe las torturas en las mazmorras del Campo Militar Número 1 , sino que también ofrece los nombres de los autores intelectuales de las operaciones y de las ejecuciones.

En enero de 1979 el procurador general de la república, Óscar Flores Sánchez, presentó los resultados de la averiguación oficial sobre desaparecidos políticos de 1971 a 1978. Aceptó que hubo trescientos catorce casos de "subversivos" —no quiso aceptar que eran guerrilleros_ que según la Procuraduría "desaparecieron y fueron víctimas de sus actos criminales, ejecutados por sus propios compañeros o se fugaron de sus cárceles" (en Castellanos: 315). El mismo Flores Sánchez terminó el informe con una declaración rotunda: "En México ni guerrilleros ni desaparecidos" (315). Esta fue la versión oficial que el Estado sostuvo y la que contradice la verdad histórica. Inclusive en 1992, Jorge Carpizo, en su calidad de presidente de la Comisión Nacional de Derechos Humanos y con el apoyo del presidente en turno, Carlos Salinas de Gortari, realizó un Informe de la investigación sobre presuntos desaparecidos en el estado de Guerrero. Es muy probable que el informe no gustara a los altos mandos de las fuerzas armadas porque fue ocultado de 1992 a 2001.

Así que por lo menos durante veinte años, Guerra en el Paraíso fue una suerte de Informe de la Verdad Histórica en el que el lector se podía enterar del proceder del ejército con nombres y datos de los lugares donde sucedieron los hechos. Si bien existía el libro de Luis Suárez, Lucio Cabañas, el guerrillero sin esperanza, obra valiosa y pionera en la documentación del Partido de los Pobres que recupera discursos transcritos de Cabañas, manifiestos de la Brigada de Ejecución y testimonios de familiares y amigos, poco habla de las tácticas de la armada mexicana y menos aún de 
los asesores extranjeros. Ni pensar que se mencionaran los nombres de los funcionarios responsables de dar la orden de que el ejército se hiciera cargo de la situación y se usaran los métodos de la "tierra rasa".

\section{La espiral del silencio}

En el momento en que sucedía la guerra sucia, los medios escritos y los electrónicos mencionaban las acciones militares como una cruzada contra el crimen organizado. La censura actuaba en todos los periódicos y revistas y el concepto de sociedad civil ni siquiera aparecía en las aulas académicas. Caímos en lo que Elisabeth Noëlle-Neumann Ilama la "espiral del silencio", que es un proceso en el que una minoría de ciudadanos decide permanecer en silencio ante un hecho para no quedarse aislados de la mayoría de personas que piensan diferente. Si bien el sistema político controlaba la opinión pública, fue una minoría la que protestó por el virtual golpe militar en el estado de Guerrero; la actitud, en general, fue que el Estado mexicano actuó conforme a derecho. Se aceptó tácitamente la versión de que los militantes del Partido de los Pobres eran delincuentes comunes. Durante casi veinte años se percibió una animadversión contra la imagen de Lucio Cabañas. Incluso la idea que queda después de leer el reportaje Lucio Cabañas, el guerrillero sin esperanza es que el profesor Cabañas fue un líder con ideas poco claras que se metió a guerrillero para imitar al Che Guevara.

A diferencia de obras narrativas como Operación masacre, de Rodolfo Walsh, que es una especie de investigación periodística, Montemayor eligió narrar de forma tal que el lector se involucrara en lo que leía (veía), es decir, que el lector se convirtiera en testigo de las torturas, delaciones, traiciones, errores y presiones políticas que se vivieron durante los años setenta en diferentes espacios tanto públicos como privados. Pongamos como ejemplo el caso de la Brigada Blanca, cuya existencia tal vez sea desconocida para los jóvenes lectores que se interesan en investigar la política social del gobierno de Luis Echeverría. Montemayor se documentó, no sabemos cómo, sobre la forma en que trabajaba y se infiltraba en los grupos subversivos esta organización criminal auspiciada por el Estado, integrada por militares y por miembros de élite de la Dirección Federal de 
Seguridad. Gracias al trabajo de Sergio Aguayo sabemos que se le asignó un presupuesto, se le dio armamento y carta blanca para violentar los derechos humanos de la población civil. Carlos Montemayor da cuenta de las torturas supervisadas por los jefes de las corporaciones: el coronel Francisco Quiroz Hermosillo, el capitán Luis de la Barreda Moreno y el policía Miguel Nazar Haro. Este grupo paramilitar actuó de manera muy similar, lo demuestra Montemayor con datos verdaderos, a los escuadrones de la muerte centroamericanos.

\section{La narratividad judicial y la narratividad ficcional}

Lo que en derecho se conoce como "teoría del caso" tiene una narratividad muy parecida a la narrativa de ficción; de hecho, se pueden confundir. Ribeiro Toral explica que en un proceso judicial: "son las narraciones, explicaciones y descripciones de los hechos parciales, fragmentadas y subjetivas, realizadas por muchas personas, las que componen la idea de realidad del caso y se encuentra controvertida por las partes" (218). Al tribunal —en nuestro caso el lector de la novela-, la teoría del caso le permite hacer una valoración de los hechos a partir de la narración novelada.

En la estructura de la "teoría del caso" hay un elemento narrativo muy importante que es la "proposición fáctica" y que es el elemento legal reformulado en un lenguaje por medio del cual el testigo puede declarar en forma "narrativa". Nuestra novela inicia con un testimonio narrado por un testigo de cargo, el secretario de gobernación Fernando Gutiérrez Barrios, quien nos informa que el gobierno de Echeverría cumplió con las condiciones que le impuso al profesor Genaro Vásquez de amnistía y exilio en La Habana, a algunos presos políticos. Pero en su declaración hay un hecho preocupante, el ejército informa que hay nueve campesinos desaparecidos: "El único contratiempo es que no aparecen nueve de los campesinos incomunicados en cuarteles militares. De los que piden los secuestradores sólo hemos localizado a seis" (Montemayor: 11). Este pasaje es un ejemplo de cómo la novela se estructura a partir de "microrrelatos" (las proposiciones fácticas) en los que intervienen muchas voces narrativas -testigos, inculpados y víctimas. Este tipo de proposiciones son "un acon- 
tecimiento discursivo" que describe una acción concreta que se traduce en narración (sigo los conceptos teóricos de Ribeiro Toral).

Los hechos y las dudas que Montemayor expone en su "teoría del caso" son las mismas que formularon los familiares de los desaparecidos hace cuarenta años y son las siguientes: legalmente el Estado acusó, persiguió y ejecutó tanto a Genaro Vázquez Rojas como a Lucio Cabañas Barrientos por los delitos de asociación delictuosa, incitación a la rebelión y homicidio. Los hechos son irrefutables, a todas luces los profesores son culpables de estas faltas, más las de secuestro y robo de bancos. Pero en la investigación del caso se presentan varias inconsistencias, por ejemplo, ¿para apresar a los líderes de las bandas delictuosas — con más de 200 seguidores-, como se presume que tuvieron Vázquez Rojas y Cabañas Barrientos era necesario desplazar a más de 20 mil efectivos militares y declarar el estado de sitio en Guerrero? ¿Era un asunto militar o judicial? ¿O estamos hablando de movimientos populares legítimos en contra de caciques protegidos por el gobierno estatal quien a su vez era respaldado por el gobierno federal? ¿Por qué no se atrapó a los culpables de las masacres ocurridas en Iguala en diciembre de 1960 y en Atoyac de Álvarez el 18 de marzo de 1967? ¿Era necesario que el ejército desalojara poblaciones enteras para atrapar a un puñado de rebeldes secuestradores que no contaban con el apoyo del pueblo? ¿Por qué el ejército empleó tácticas antiguerrilleras como si se enfrentara a un ejército formal? ¿Hubo presión y asesoría de Washington para sofocar la rebelión? Montemayor hace hablar a los testigos para responder a estas dudas y demostrar lo que ya todos sabemos.

Por el lado de los agresores o víctimas, según lo vea el fiscal-lector, también somos testigos de los extremos de violencia a los que llegaron, particularmente con el intento de secuestro, que terminó en el asesinato del empresario Eugenio Garza Sada. Los involucrados, a través de los ojos del novelista como "testigo vicario", presentan pruebas y descargos de su actuación a favor o en contra del gobierno. Uno de los factores de la petición de la "mano dura" del gobierno fue que el sector empresarial demandó que se castigara con todo el rigor de la ley a los responsables de la muerte del empresario Eugenio Garza Sada. Durante el entierro del empresario el orador oficial, el abogado Ricardo Margaín Zozaya, amenaza al gobierno de Luis Echeverría: 
Cuando se ha propiciado desde el poder, a base de declaraciones y discursos, el ataque reiterado al sector privado, del cual formaba parte destacada el occiso, sin otra finalidad aparente que fomentar la división y el odio entre las clases sociales. Cuando no se desaprovecha ocasión para favorecer y ayudar a todo cuanto tenga relación con las ideas marxistas a sabiendas de que el pueblo mexicano repudia este sistema por opresor [...]

[...] Urge que el gobierno cambie de rumbo [...] para que renazca la confianza en el pueblo mexicano. Poner un hasta aquí a quienes mediante agitaciones estériles y actos delictivos y declaraciones oficiales injuriosas, amenazan con socavar los cimientos de la patria. Es un deber ineludible (163).

Recordemos que el 18 de septiembre de 1973, una célula militar de la Liga Comunista 23 de Septiembre, al intentar secuestrar al empresario Garza Sada, terminó asesinándolo. El millonario regiomontano y el presidente Echeverría tenían una relación muy tensa, sino es que de franco enfrentamiento. Garza Sada, aliado con el grupo Monterrey, disputaba con el gobierno el control de los periódicos, que era un monopolio del estado. Como respuesta al secuestro de Garza Sada, el gobierno endureció su política y ordenó arrasar con los focos guerrilleros junto con sus simpatizantes. Laura Castellanos nos informa que durante el sexenio en cuestión fueron enviados a la Escuela de las Américas ${ }^{5}$ — famosa por preparar a los mejores torturadores sudamericanos - "veintiocho oficiales que tomarán cursos de inteligencia militar, contrainteligencia, guerra irregular y operaciones de la selva, que actuarán principalmente en Guerrero" (125).

Los diálogos del general Cuenca Díaz están sacados de las declaraciones que en su momento hizo a la prensa escrita, en los que explica que "el ejército en Guerrero sólo desempeña actividades sociales. Lleva alimentos, medicinas, agua, a los lugares más remotos de la sierra. Ésa es nuestra labor. Porque en Guerrero nadie apoya a Vásquez Rojas. Él conoce bien la sierra y se mueve de un sitio a otro, como bandido" (Montemayor: 13). El trabajo de archivo documenta también que los Ilamados "vuelos

5 Augusto Varas (1988) nos informa que el nombre original de esta escuela militar era Instituto del Hemisferio Occidental para la Cooperación en Seguridad; fue fundada en 1946 y se especializó en formar cuadros antisubversivos de las dictaduras chilena y argentina. En julio de 1963 cambió de nombre al de United States Army School of The Americas. Actualmente, la sede se encuentra en Fort Benning, en el estado de Columbus, Georgia. 
de la muerte" fueron implementados por los generales Acosta Chaparro, Quirós Hermosillo y Francisco Javier Barquín Alonso. El capitán Margarito Monroy Candia, apenas en el año 2000 declaró:

La persona era sacada de un cuartito que estaba dentro de la base aérea, a unos veinte o treinta metros de donde los ejecutaban, vendada de los ojos y la sentaban en un banquito, y de ahí alguien se le acercaba por detrás y le daba un balazo en la nuca. A mí me toco darme cuenta la primera ocasión cuando mi general Quirós Hermosillo disparó a varias gentes, me acuerdo bien, cuando lo tenía, lo vi con la camiseta manchada de sangre. Por eso yo entre el personal le puse el Verdugo, y a la pistola que usaba para matar gente, que por cierto era una Uzi 9 milímetros, le puse "La espada vengadora", ya que hasta donde sé la habían traído de Israel (Castellanos: 161).

Montemayor narra el episodio del avión de la muerte en contrapunto con las penurias que pasaba La Brigada de Ajusticiamiento en la sierra de Atoyac. En la ficción no es un avión desde donde arrojan los cuerpos, sino un helicóptero en donde ejecutan a los sospechosos. Cuando se recuperan los restos humanos en las playas los militares intimidan a los pescadores y los obligan a guardar silencio para que no haya represalias:

Bueno [explica un pescador al capitán interrogador] es que los hemos visto varios de nosotros, pues. El mar ha estado aventando pedazos de ropa, de pantalones, de vestidos de mujer. $Y$ huesos de gente, pues [...]

[...] Es basura que viene de otra parte —interrumpió el capitán-. Porque nadie puede asegurar que sea de gente que haya caído al mar. Porque nuestros helicópteros sólo arrojan arena. ¿Lo oyen ustedes? Los de allá, ustedes, ¿lo oyen? ¿Lo oyen todos? Aquí nadie debe decir mentiras. Quiero que esto quede bien claro. Sobre todo porque aquí la gente viene a divertirse, ¿no? (165).

Un hecho innegable es que gracias a las novelas de Montemayor, el tema de la guerrilla (tanto la de Chihuahua como la de Guerrero) volvieron a entrar a la palestra política. Pero sobre todo han sido los periodistas quienes, a partir del 2000, año en que se abrieron al público los archivos que contienen los documentos militares, han dado a conocer los informes oficiales de las operaciones militares contra Lucio Cabañas.

Tal vez para muchos la guerra sucia o guerra de baja intensidad haya sido un episodio sin importancia en la historia nacional, y se cayó en el 
error de "trivializar el mal" al pensar que el ejército cumplió con su deber y que los subversivos se lo merecían. Podríamos citar varios periodistas de los medios audiovisuales que difundieron esta versión de la historia, pero los testimonios de sobrevivientes y la memoria colectiva, incluso novelas como Guerra en el Paraíso, que toma prestado el testimonio de los derrotados y lo convierte, por medio de la ficción realista, en "memoria vicaria" están cumpliendo con la misión de recordar los delitos que cometió el ejército en nombre de la paz social y la seguridad social y cuyos autores materiales e intelectuales quedaron impunes.

\section{El lector como juez de la historia}

Contar es lo mismo que convencer o hacerse entender o hacer ver y así puede ser comprendido, hasta lo más infame, todo perdonado cuando hay algo que perdonar, todo pasado por alto y aun compadecido.

JAVIER MARÍAS. Mañana en la batalla piensa en mí (1994)

Carlos Montemayor no desconocía la retórica judicial, y por ende, el arte de convencer a un jurado. Si asumimos que el novelista recurrió a argumentaciones judiciales, como presentación de pruebas y de evidencias forenses, debemos empezar suponiendo, también, que la información que utiliza es verdadera — como se demostró con los años, ningún dato utilizado fue ficción. Partimos de la condición de la veracidad de las pruebas en este "juicio novelado". Segunda condición argumental que el autor presenta al lector: "la información presentada es de relevancia pública". Uno de los recursos empleados por Montemayor es de los "alegatos" y explicaciones de operaciones militares y decisiones políticas, no es a causa de razones "didácticas" de instruir al público sino de aportar pruebas contundentes de los crímenes cometidos para que el "jurado" —el lector- emita un juicio final.

Una de las estrategias de Montemayor es "manejar" el "ojo del lector" para convertirlo en testigo de las torturas y en público de las arengas de los políticos. El arte y la opinión pública trabajaron por mucho tiempo para abrir el litigio en contra de los torturadores. Son significativas y paralelas a 
la novela de Montemayor obras con un gran trabajo de archivo, denuncia y memoria colectiva como El crimen político en México (1994), de Juan Pablo de Tavira, quien fuera director del Penal de Almoloya y que conoció a muchos guerrilleros en el penal de Lecumberri. En repetidas ocasiones hizo denuncias sobre abusos del poder durante los gobiernos de Salinas de Gortari y Ernesto Zedillo; el legista fue asesinado en 2000. En la mencionada obra, De Tavira entrevistó a Alberto Ulloa Bornemann, ${ }^{6}$ quien fuera colaborador de Lucio Cabañas y purgara prisión por subversión, secuestro y terrorismo en la cárcel de Lecumberri, en el reclusorio Oriente y en el de Santa Martha Acatitla; Ulloa Bornemann denunció las torturas a las que fue sometido y de las que fue testigo en el Campo Militar Número 1.

Cuando se publicó la primera edición de Guerra en el Paraíso no teníamos el horizonte de expectativas que trajo el cambio de régimen del año 2000 y la promesa de integrar una Comisión de la Verdad que llevara un proceso legal para llenar las lagunas legales. Hoy día, en el 2018, no hay un solo culpable en la cárcel y el ejército no ha reconocido oficialmente que hubo una guerra sucia. Hay dos nuevas generaciones de lectores que deben tener presente los márgenes de la historia de la Guerra en el Paraíso, que quizá no sepan lo que era, en términos bélicos, el exterminio tipo "aldea vietnamita". En una de las "proposiciones fácticas", se hace alusión a otro personaje culpable de lesa humanidad, el coronel Alfredo Cassani Mariña. Juan Veledíaz (artículo consultado en línea: <http://www. estadomayor.mx/48503>) nos informa que este militar fue el que aplicó en la sierra de Atoyac ${ }^{7}$ el método de la "aldea vietnamita", es decir, que era cuando una población que presuntamente apoyaba a la guerrilla era evacuada y posteriormente esos terrenos desalojados eran sometidos a bombardeo aéreo.

6 En 2004, Alberto Ulloa Bornemann publicó su libro de memorias Sendero en tinieblas, en donde relata sus días en prisión y rememora algunos pasajes de la vida guerrillera al lado de Lucio Cabañas. El libro fue traducido al inglés como Sobreviviendo la guerra sucia de México (Surviving Mexico's Dirty War); el gesto de no mencionar la "guerra sucia" en la versión original no deja de ser inquietante.

7 Juan Veledíaz acota que la historia del 27 de Infantería es particularmente atroz, pues en su historial está tanto la desaparición de 300 campesinos durante la guerra de baja intensidad en los setenta como la desaparición de los 43 estudiantes de Ayotzinapa en 2014. Para más detalles véase Veledíaz 2012. 
Otro personaje clave en la guerra sucia por su sadismo, fue el general Salvador Rangel Media, quien dirigió un grupo paramilitar que secuestraba, torturaba y ejecutaba a civiles que presuntamente eran seguidores de Lucio Cabañas. El grupo en cuestión fue conocido como "Sangre" y el sello particular de este comando era que a las víctimas las hacían beber gasolina y luego les prendían fuego (Petrich 2014).

Casi al final de la novela se entabla un diálogo entre los altos mandos del ejército: el coronel De la Selva y el general Escárcega. La escena ocurre en el Casino Militar después de una comilona; es un contrapunto entre un militar que defiende la fuerza del Estado y otro que le concede al pueblo el derecho a rebelarse contra el mal gobierno. El lector está en las entrañas misma del poder militar y por fin llega a la verdad última de los motivos secretos del ejército para eliminar al pueblo llano: “Debemos aceptar que el pueblo, o al menos un sector del pueblo, está detrás de Lucio, que apoya su lucha. Que sean narcotraficantes, robavacas o no, eso no importa. Lo que debe quedarnos claro es que parte del pueblo está apoyando su lucha y que es pueblo. Y esto es lo que algunos políticos se resisten a aceptar. Por eso temen las medidas militares. Hacia esto vas, ¿no es así, Rafael?" (Montemayor: 351). Al final de la escena, se llega a la conclusión de que el ejército cumplió con su deber, pero queda la culpa de haber reprimido al pueblo: "Tenemos que hacerlo, por supuesto. Y no puede escapar del ejército [Lucio Cabañas]. Eso lo sabemos muy bien. Pero se trata del pueblo" (357). Esta es la versión de la cúpula vista desde la lejanía de la ciudad; en el siguiente episodio somos testigos de la cacería de Lucio Cabañas y de cómo el ejército cumple con eficiencia la "limpieza" de seguidores de los guerrilleros. Hay un contrapunto entre las razones políticas y la manera violenta de aplicar el cumplimiento de las órdenes. Una es la razón de Estado que debe cuidar a toda costa el orden social, en el discurso, y en los hechos vemos que se eliminan a los pueblos que no se someten a las razones del gobierno. Este enfrentamiento entre discursos y hechos es una de las tácticas "jurídicas" que sigue Montemayor: el acusado explica su proceder, pero la verdad, los hechos, lo desmienten. Este procedimiento narrativo es la espina dorsal de un juicio penal y está dividida en tres partes: "la hipótesis fáctica (los hechos penalmente relevantes), la hipótesis jurídica (los fundamentos jurídicos que los describen) y la hipótesis pro- 
batoria (las pruebas que sustentan esa afirmación)" (Ribeiro Toral: 219). Somos testigos de las hipótesis fácticas que nos demuestran que a pesar de que el ejército haya cumplido órdenes del Estado Mayor Presidencial, se cometieron crímenes premeditados que fueron ocultados a la opinión pública.

No podemos negar que un discurso democrático se fue forjando en muchas disciplinas sociales y humanísticas y no sólo en la prensa escrita y electrónica; la literatura no es la excepción; Guerra en el Paraíso, al incluir en la agenda democrática el esclarecimiento de los crímenes de lesa humanidad que cometió el ejército, cumple con esa misión que sigue inconclusa. Es interesante estudiar cómo algunas obras narrativas adquieren la forma que le piden los reclamos sociales; por lo menos esa es la tesis que sostengo respecto a esta obra de Carlos Montemayor. Aunque en sus inicios se tomó como una novela testimonial, la retórica nos demuestra que la manera en que está narrada la guerra sucia es un intento para convencer a un público culto de que Lucio Cabañas no fue un rebelde extraviado del comunismo autoritario, sino que su rebelión tenía profundos reclamos populares y que la guerra sucia es un asunto que todavía le duele al Estado, como lo demuestra el cierre de los archivos secretos de la Defensa Nacional, con lo que un capítulo importante de la historia del autoritarismo presidencial queda pendiente.

\section{Bibliografía}

CALvo, José. Derecho y narración. Materiales para una teoría y crítica narrativista del Derecho. Barcelona: Ariel, 1996.

Castellanos, Laura. México armado (1943-1981). México: Era, 2011.

Galindo de Pablo, Adrián. "Guerra de baja intensidad", en Animal Político. Artículo disponible en línea en: <https://www.animalpolitico.com/bloguerosverdad-justicia-reparacion/2015/02/02/guerra-de-baja-intensidad/\#_ftn4> [consultado el 21 de abril de 2018].

García Ramírez, Fernando. "Compromisos", en Vuelta, 183 (febrero de 1992): 39.

Illades, Carlos y Teresa SANTIAgo. Estado de guerra. De la guerra sucia a la narcoguerra. México: Era, 2014.

Mendoza García, Jorge. "La tortura en el marco de la guerra sucia en México: un ejercicio de memoria colectiva", en Polis. Investigación y Análisis Socio- 
político y Psicosocial. México: Universidad Autónoma Metropolitana Unidad Iztapalapa. Vol. 7-2 (2011): 139-179.

Montemayor, Carlos. Guerra en el Paraíso. México: Diana, 1991.

Noëlle-Neumann, Elisabeth. La espiral del silencio. Opinión pública nuestra piel social. Javier Ruiz Calderón (trad.). Barcelona: Paidós, 1995.

Petrich, Blanche. "En 1974 operó en Guerrero un grupo paramilitar que interrogaba e incineraba sospechosos", en La Jornada. México (17 de octubre de 2014). Artículo disponible en línea en: <http://www.jornada.unam.mx/2014/10/17/ politica/013n1 pol> [consultado el 28 de abril de 2018].

Pliego, Roberto. "Los pasos de Lucio", en Nexos. México (1 de julio de 1991). Disponible en línea en: <https://www.nexos.com.mx/?p=6229> [consultado el 15 de abril de 2018].

Ribeiro TORAL, GeRARDO. “La construcción retórica de la realidad en los juicios orales", en Revista de Derecho. Montevideo: Universidad Católica del Uruguay. 11 (julio de 2015): 211-231.

Sarlo, Beatriz. Tiempo pasado. Cultura de la memoria y giro subjetivo. Una discusión. México: Siglo XXI, 2007.

SuÁrez, Luis. Lucio Cabañas, el guerrillero sin esperanza. México: Grijalbo, 1980.

VAras, Augusto. La autonomía militar en América Latina. Buenos Aires: Nueva Sociedad, 1988.

VeledíAz, JuAn. El general sin memoria. Una crónica de los silencios del ejército mexicano. México: Debate, 2012.

Zazueta Aguilar, Humberto y otros. La guerra sucia en México y el papel del Poder Legislativo. Comparativo internacional. México: Cámara de Diputados, 2009.

José Eduardo Serrato Córdova

Es doctor en Literatura Latinoamericana por la Universidad Nacional Autónoma de México. Investigador del Centro de Estudios Literarios del Instituto de Investigaciones Filológicas. Es profesor del Posgrado en Letras de la Facultad de Filosofía y Letras y autor de los libros: Los sueños de la razón. Ensayos de poética y profética de Luis Aragón; Crónicas cinematográficas: 1935-1936; Las tramas de la parodia. El desfile del amor, de Sergio Pitol; La boca de polen. Una biografía de Luis Cardoza y Aragón. Actualmente realiza una investigación sobre la violencia y la literatura mexicana del siglo XXI. Fue secretario de redacción de la revista Literatura Mexicana de 2002 a 2015. 